\title{
Prevalence of Lipodystrophy and Metabolic Abnormalities in HIV-infected African Children after 3 Years on First-line Antiretroviral Therapy
}

\author{
Mutsawashe Bwakura-Dangarembizi, MMed, *Victor Musiime, PhD, $†$ Alexander J. Szubert, MSc, $\S$ \\ Andrew J. Prendergast, Dphil, § Zvenyika A. Gomo, PhD, * Margaret J. Thomason, PhD, $\S$ \\ Cuthbert Musarurwa, MSc, * Peter Mugyenyi, FRCP,† Patricia Nahirya, MMed,ll Adeodata Kekitiinwa, MMed, ** \\ Diana M. Gibb, MD, § Ann S. Walker, PhD, $\S$ and Kusum Nathoo, MRCP*, for the ARROW Trial Team
}

\begin{abstract}
Background: Most pediatric lipodystrophy data come from high-income/ middle-income countries, but most HIV-infected children live in sub-Saharan Africa, where lipodystrophy studies have predominantly investigated stavudine-based regimens.

Methods: Three years after antiretroviral therapy (ART) initiation, body circumferences and skinfold thicknesses were measured $(\mathrm{n}=590)$, and fasted lipid profile assayed $(n=325)$, in children from 2 ARROW trial centres in Uganda/Zimbabwe. Analyses compared randomization to long-term versus short-term versus no zidovudine from ART initiation [unadjusted; latter 2 groups receiving abacavir+lamivudine+non-nucleoside-reversetransciptase-inhibitor (nNRTI) long-term], and nonrandomized (confounder-adjusted) receipt of nevirapine versus efavirenz.

Results: Body circumferences and skinfold thicknesses were similar regardless of zidovudine exposure $(P>0.1)$, except for subscapular and supra-iliac skinfolds-for-age which were greater with long-term zidovudine $(0.006<$ $P<0.047)$. Circumferences/skinfolds were also similar with efavirenz and nevirapine (adjusted $P>0.09 ; 0.02<P<0.03$ for waist/waist-hip-ratio). Total and high-density lipoprotein (HDL)-cholesterol, HDL/triglycerideratio $(P<0.0001)$ and triglycerides $(P=0.01)$ were lower with long-term zidovudine. Low-density lipoprotein (LDL)-cholesterol was higher with efavirenz than nevirapine $(P<0.001)$. Most lipids remained within normal ranges ( $75 \%$ cholesterol, $85 \%$ LDL and $100 \%$ triglycerides) but more on long-term zidovudine (3 NRTI) had abnormal HDL-cholesterol ( $88 \%$ vs. $40 \%$ short/no-zidovudine, $P<0.0001)$. Only $8 / 579(1.4 \%)$ children had clinical fat wasting (5 grade $1 ; 3$ grade 2$) ; 2(0.3 \%)$ had grade 1 fat accumulation. Conclusions: Long-term zidovudine-based ART is associated with similar body circumferences and skinfold thicknesses to abacavir-based ART,
\end{abstract}

Accepted for publication June 27, 2014.

M.B.-D., V.M., D.M.G., A.S.W. and K.N. contributed equally to this study.

*University of Zimbabwe, College of Health Sciences, Harare, Zimbabwe; $\dagger$ Joint Clinical Research Centre; \$Makerere University, College of Health Sciences, Kampala, Uganda; §Medical Research Council Clinical Trials Unit; $\uparrow$ Centre for Paediatrics, Blizard Institute, Queen Mary University of London, London, United Kingdom; /Medical Research Council/ Uganda Virus Research Institute Uganda Research Unit on AIDS, Entebbe, Uganda; and **Pediatric Infectious Diseases Clinic/Baylor - Uganda, Mulago Hospital, Kampala, Uganda

M. Bwakura-Dangarembizi and V. Musiime contributely equally to this work. D. M. Gibb, A. S. Walker, and K. Nathoo contributed equally to this work.

A.J.P. is funded by the Wellcome Trust (WT 093768/z/10/z). No competing interests exist for the other authors.

The main ARROW trial was funded by the UK Medical Research Council and the UK Department for International Development (DFID). ViiV Healthcare/GlaxoSmithKline donated first-line drugs for ARROW and provided funding for VL assays. Additional funding for the metabolic sub-study was obtained from Wellcome Trust, UK through Southern Africa Centre for Research Excellence (SACORE) at the UZCHS.

Address for correspondence: Victor Musiime, PhD, Joint Clinical Research Centre (JCRC), Plot 101 Lubowa Estates, off Entebbe road, P.O. Box 10005, Kampala, Uganda. E-mail: musiimev@yahoo.co.uk.

Copyright (C) 2014 by Wolters Kluwer Health, Inc. All rights reserved.

ISSN: 0891-3668/15/3402-0e23

DOI: $10.1097 /$ INF.0000000000000491 with low rates of lipid abnormalities and clinical lipodystrophy, providing reassurance where national programs now recommend long-term zidovudine. Efavirenz and nevirapine were also similar; however, the higher LDL observed with efavirenz and lower HDL observed with zidovudine suggests that zidovudine+lamivudine+efavirenz should be investigated in future.

Key Words: HIV, Africa, children, antiretroviral therapy, lipodystrophy, lipids

(Pediatr Infect Dis J 2015;34:e23-e31)

T he lipodystrophy syndrome, which includes central lipohypertrophy, lipoatrophy of extremities, face and buttocks, and metabolic abnormalities, has been reported among naive and experienced HIVinfected children on antiretroviral therapy (ART) in resource-rich and resource-limited settings. ${ }^{1-14}$ Observed risk factors in children include: use of stavudine and protease inhibitors; advanced HIV disease, high viral loads and low CD4; duration of HIV infection/older age; puberty; female gender; white ethnicity; high body mass index (BMI); and rapid immunological recovery post-ART. ${ }^{1,2,4,6,8,13-18}$

Much lipodystrophy data in children come from middleincome/high-income countries, whereas $>90 \%$ of HIV-infected children live in sub-Saharan Africa ${ }^{19}$ where underlying malnutrition, micronutrient deficiencies, co-infections and advanced HIV disease are more prevalent. Lipodystrophy studies specifically among sub-Sarahan African children are thus needed. Two recent cross-sectional studies in Uganda and Tanzania reported clinically ascertained lipodystrophy in $27-34 \%$ children, although most cases were mild ${ }^{13,14}$; a third cross-sectional randomized comparison of nevirapine versus lopinavir-containing ART reported lipodystrophy in $8.4 \%{ }^{20}$ Importantly, most ${ }^{13,14}$ or all ${ }^{20}$ children had substantial stavudine exposure, which was associated with lipodystrophy, ${ }^{13,14}$ similar to a cross-sectional study of skinfolds/circumferences in Ugandan/Zambian children. ${ }^{21}$

Many African ART programs are moving away from stavudine-containing regimens in children, as in adults. ${ }^{22-24}$ Children now predominantly receive zidovudine-containing regimens, as concerns remain about tenofovir's impact on bone metabolism and renal function, ${ }^{25,26}$ and abacavir remains expensive. ${ }^{27}$ Like stavudine, zidovudine is a thymidine-analog nucleoside reverse transcriptase inhibitor (NRTI) so could potentially lead to lipodystrophy, albeit at lower rates. ${ }^{13,14,28}$ Non-nucleoside reverse transcriptase inhibitors (NNRTIs) have also been associated with lipodystrophy, ${ }^{1}$ with, if anything, higher rates in those receiving nevirapine versus efavirenz. ${ }^{29,30}$

Here, we investigate the contribution of zidovudine and efavirenz/nevirapine to body circumferences, skinfold thicknesses, metabolic parameters and clinically determined lipodystrophy, in randomized (zidovudine) and nonrandomized (efavirenz/nevirapine) comparisons 3 years after ART initiation in the ARROW trial. ${ }^{31}$ 


\section{METHODS}

In ARROW (ISRCTN24791884), previously untreated Ugandan/Zimbabwean children/adolescents age 3 months to 17 years, eligible for ART using World Health Organization (WHO) 2006 criteria, ${ }^{32}$ were randomized $1: 1$ to clinically driven monitoring versus laboratory plus clinical monitoring for toxicity (hematology/biochemistry) and efficacy (CD4). Children were also randomized 1:1:1 in a factorial design to open-label lamivudine+abacavir+NNRTI continuously (Arm-A, no zidovudine); induction-maintenance with 4-drug lamivudine+abacavir+NNRTI+zidovudine for 36 weeks, followed by lamivudine+abacavir+NNRTI (Arm-B; short-term zidovudine) or lamivudine+abacavir+zidovudine (Arm-C; longterm zidovudine). The NNRTI (nevirapine/efavirenz) was chosen by clinicians according to local availability (varying by country) and age. Caregivers gave written consent; older children (8-17 years) aware of their HIV status also gave assent or consent following national guidelines. ARROW was approved by Research Ethics Committees in Uganda, Zimbabwe and the UK. Children were recruited from 3 centers in Uganda [Joint Clinical Research Centre, Kampala; Baylor-Uganda, Mulago and MRC/UVRI Uganda Research Unit on AIDS, Entebbe], and 1 in Zimbabwe (University of Zimbabwe, Harare).

Two centers (Joint Clinical Research Centre and Harare) undertook a metabolic sub-study with a separate protocol (approved by Research Ethics Committees in both countries) and consent/assent as above. The primary sub-study cross-sectional objective was to compare children randomized to long-term zidovudine-containing ART with short-term zidovudine-containing or nonzidovudine-containing ART in terms of prevalence of the lipodystrophy syndrome 3 years after ART initiation. At the scheduled visit 3 years (156 weeks) after ART initiation, questionnaires were completed by the caregiver and physician (same for all visits); body circumferences (waist, hip, mid-thigh, mid-upper-arm) and skinfold thicknesses (triceps, subscapular, supra-iliac, mid-thigh) were measured by 1 nurse at each site; and blood taken (no intake other than water for 6 hours prior, wherever possible) for total cholesterol and triglycerides in real-time, and in batched retrospective analysis lipid fractions [directly assayed high-density lipoprotein (HDL) and low-density lipoprotein (LDL)], glucose, total protein and albumin (Harare only). For circumferences and skinfold thicknesses, procedures were standardized with prespecified positions for 3 repeated measurements to reduce interoperator and intervisit variability, following the Anthropometric Standardization Manual, ${ }^{33}$ using T/W callipers (Holtain limited, Crymych, UK) for skin-fold thicknesses. Waist and hip circumferences were also collected every 4-6 weeks in all ARROW children.

\section{Analysis}

Analysis used the mean of the 3 measurements at the visit nearest to 3 -years from ART initiation within \pm 24 weeks. As no African reference data were available, Z-scores were determined using Dutch reference values and analyses focused on differences between groups. ${ }^{34,35}$ No reference data was available for mid-thigh skinfold thickness. Weight-for-age and height-for-age were calculated using UK reference ranges. ${ }^{36}$ Total and LDL cholesterol, triglycerides, glucose and albumin were considered abnormal according to $^{37}$; HDL was considered abnormal if $<1.04 \mathrm{mmol} / \mathrm{L}^{38}$

Randomized ART strategy groups were compared using $\chi^{2}$ or exact tests for categorical factors and one-way analysis of variance for continuous values. Randomization means these unadjusted comparisons are unbiased in expectation; there was no evidence of chance imbalances in pre-ART factors across groups $(P>0.3)$. A nonrandomized comparison of nevirapine versus efavirenz was also undertaken in children $\geq 3$ years at ART initiation (no efavirenz dose for $<3$ years at the time), adjusted for potential confounders: age at 3-year measurement, sex, center, ART-strategy randomization, calendar year of ART initiation, pre-ART CD4\% and any change in NNRTI from initiation. Absolute Z-scores for waist/hip circumferences measured in all children $(n=1206)$ were also compared using generalized estimating equations (normal distribution, independent working correlation, closest measurement to 12-week timepoints in equally spaced windows) (models for change from baseline in the subset enrolled from May 2008 when measurements started were similar, data not shown).

Predictors of the sum of the skinfolds were considered using normal linear regression with backward elimination (exit $P=0.05$ ) on the factors above plus pre-ART WHO stage; monitoring randomization; and CD4\%, height and BMI for age at ART initiation, 3 -years and change during the first 6 months on ART. ART-strategy randomization was included regardless of significance. Weight-forage was not considered as it was strongly associated with heightfor-age (Spearman correlation $\geq 0.74$ ). Only $56 \%$ children had HIV viral load assayed at 3 years, so this was not considered. Nonlinearity in effects of continuous predictors was explored using natural cubic splines ( 3 knots at 10th, 50th and 90th centiles). Children were grouped by body circumference/skinfold Z-scores ( 7 measurements/child) using complete-linkage cluster analysis. All analyses were performed using Stata 12.1 (StataCorp). All $P$-values are two-sided. No adjustment was made a priori for multiple testing.

\section{RESULTS}

Seven hundred and eighteen ARROW children were enrolled (March 2007-October 2008) at metabolic sub-study centers; 686 were alive in follow-up 3 years later (27 deaths and 5 lost). Five hundred and ninety-two $(86.3 \%)$ had 3-year measurements (remainder had measurements outside the window, or did not consent/were not approached, for example, if older children were unaccompanied). Two previously pregnant participants were excluded, leaving 590 in analyses, age median 9 years (range, 3-19).

Children had initiated ART $(23.9 \%$ aged $<3)$ with advanced disease, but recovered well (Table 1). Children randomized to Arms A, B and C had spent $3.5 \%, 24.8 \%$ and $96.5 \%$ child-time on zidovudine-containing ART, respectively, by the 3-year measurement. Arm A/B children $>3$ years at ART initiation and on nevirapine/ efavirenz at 3 years had spent $99.1 \%$ and $98.1 \%$ child-time on nevirapine or efavirenz, respectively. At ART initiation and 3 years subsequently, only 5 and 2 children had BMI-for-age Z-score $>2$ (maximum BMI 23 and 19), respectively.

\section{Anthropometric Measurements}

After 3 years on ART, few children had measurements $\leq 5$ th percentile of Dutch reference ranges for central measures $[0 / 576$ (0.0\%) waist circumference; $34 / 578$ (5.9\%) hip; 33/577 (5.7\%) subscapular and 16/578 (2.8\%) supra-iliac skinfold thickness]. Substantial proportions were $\leq 5$ th percentile for extremities $[402 / 576$ $(69.8 \%)$ mid-thigh and 190/579 (32.8\%) mid-upper arm circumference; $144 / 578(24.9 \%)$ triceps skinfold thickness]. However, proportions were similar in children receiving long-term zidovudine $(71.2 \%, 32.8 \%, 22.1 \%$, respectively) and not receiving long-term zidovudine (ie, receiving long-term abacavir; $69.1 \%, 32.8 \%, 26.3 \%$ respectively; $P>0.3$ ); $<1 \%$ measurements were $\geq 95$ th percentile on any measure.

There were no significant differences by randomized ARTstrategy, or long-term zidovudine (Arm-C) versus no or short-term zidovudine combined (ArmsA/B), for any body circumference $(P>0.5$; $\mathrm{Z}$-score $P>0.6)$, waist-hip ratio $(P>0.14$; Z-score, $P>0.6)$, or waist-arm ratio $(P>0.6)$ (Table 1$)$. There were also no significant differences in skinfold thicknesses or triceps skinfold Z-score 
TABLE 1. Characteristics at ART Initiation and at 3-year Measurement

\begin{tabular}{|c|c|c|c|}
\hline & $\begin{array}{l}\text { Total } \\
\mathrm{N}=590\end{array}$ & $\begin{array}{l}\text { JCRC } \\
\mathrm{N}=265\end{array}$ & $\begin{array}{l}\text { Harare } \\
\mathrm{N}=325\end{array}$ \\
\hline Male & $300(50.8 \%)$ & $129(48.7 \%)$ & $171(52.6 \%)$ \\
\hline \multicolumn{4}{|l|}{ At ART initiation } \\
\hline Age $<3$ years & $141(23.9 \%)$ & $77(29.1 \%)$ & $64(19.7 \%)$ \\
\hline CD4: median (IQR) & $318(168,583)$ & $362(181,636)$ & $305(160,540)$ \\
\hline CD4\%: median (IQR) & $12(7,16)$ & $14(8,18)$ & $11(7,15)$ \\
\hline Weight-for-age Z-score: median (IQR) & $-2.1(-3.2,-1.2)$ & $-1.7(-2.8,-1.0)$ & $-2.5(-3.6,-1.5)$ \\
\hline Height-for-age Z-score: median (IQR) & $-2.4(-3.3,-1.6)$ & $-2.0(-2.9,-1.1)$ & $-2.8(-3.5,-1.9)$ \\
\hline BMI-for-age Z-score: median (IQR) & $-0.8(-1.6,0.0)$ & $-0.7(-1.5,0.0)$ & $-0.8(-1.8,0.0)$ \\
\hline \multicolumn{4}{|l|}{ WHO stage } \\
\hline $1 / 2$ & $174(29.5 \%)$ & $135(50.9 \%)$ & $39(12.0 \%)$ \\
\hline 3 & $347(58.8 \%)$ & $97(36.6 \%)$ & $250(76.9 \%)$ \\
\hline 4 & $69(11.7 \%)$ & $33(12.5 \%)$ & $36(11.1 \%)$ \\
\hline \multicolumn{4}{|l|}{ Randomized treatment strategy } \\
\hline Arm A (3TC/ABC/NNRTI throughout) & $195(33.1 \%)$ & $89(33.6 \%)$ & $106(32.6 \%)$ \\
\hline Arm B ( 36 weeks ZDV) & $201(34.1 \%)$ & $90(34.0 \%)$ & $111(34.2 \%)$ \\
\hline Arm C (long-term ZDV) & $194(32.9 \%)$ & $86(32.5 \%)$ & $108(33.2 \%)$ \\
\hline \multicolumn{4}{|l|}{ Allocated monitoring strategy } \\
\hline Laboratory and clinical monitoring (routine CD4 monitoring) & $290(49.2 \%)$ & $130(49.1 \%)$ & $160(49.2 \%)$ \\
\hline Clinically driven monitoring (no CD4 monitoring) & $300(50.8 \%)$ & $135(50.9 \%)$ & $165(50.8 \%)$ \\
\hline \multicolumn{4}{|l|}{ Three-year measurement } \\
\hline Years on ART: median (IQR) & $3.0(3.0,3.0)$ & $3.0(3.0,3.0)$ & $3.0(2.8,3.1)$ \\
\hline Age: median (IQR) & $9.7(6.0,12.6)$ & $8.9(5.6,12.4)$ & $10.6(6.5,12.7)$ \\
\hline \multicolumn{4}{|l|}{ ART combination } \\
\hline $3 \mathrm{TC}+\mathrm{ABC}+\mathrm{NVP}$ & $210(35.6 \%)$ & $56(21.1 \%)$ & $154(47.4 \%)$ \\
\hline $3 \mathrm{TC}+\mathrm{ABC}+\mathrm{EFV}$ & $177(30.0 \%)$ & $119(44.9 \%)$ & $58(17.8 \%)$ \\
\hline $3 \mathrm{TC}+\mathrm{ABC}+\mathrm{ZDV}$ & $190(32.2 \%)$ & $88(33.2 \%)$ & $102(31.4 \%)$ \\
\hline Other NVP-containing first-line & $1(0.2 \%)$ & $0(0.0 \%)$ & $1(0.3 \%)$ \\
\hline None* & $1(0.2 \%)$ & $1(0.4 \%)$ & $0(0.0 \%)$ \\
\hline 2NRTI+ALV & $10(1.7 \%)$ & $1(0.4 \%)$ & $9(2.8 \%)$ \\
\hline $\mathrm{EFV}+\mathrm{ALV}$ & $1(0.2 \%)$ & $0(0.0 \%)$ & $1(0.3 \%)$ \\
\hline \multicolumn{4}{|l|}{ Tanner stage } \\
\hline 1 & $109(18.5 \%)$ & $30(11.3 \%)$ & $79(24.3 \%)$ \\
\hline 2 & $76(12.9 \%)$ & $32(12.1 \%)$ & $44(13.5 \%)$ \\
\hline 3 & $49(8.3 \%)$ & $19(7.2 \%)$ & $30(9.2 \%)$ \\
\hline $4-5$ & $48(8.1 \%)$ & $29(10.9 \%)$ & $19(5.8 \%)$ \\
\hline$>=10$ years but not staged & $2(0.3 \%)$ & $1(0.4 \%)$ & $1(0.3 \%)$ \\
\hline$<10$ years at 3 -year measurement & $306(51.9 \%)$ & $154(58.1 \%)$ & $152(46.8 \%)$ \\
\hline CD4: median (IQR) & $780(543,1092)$ & $850(575,1209)$ & $750(533,1019)$ \\
\hline $\mathrm{CD} 4 \%>10 \%$ above pre-ART & $525(89.0 \%)$ & $226(85.3 \%)$ & $299(92.0 \%)$ \\
\hline Weight-for-age Z-score: median (IQR) & $-1.3(-2.1,-0.6)$ & $-1.2(-1.9,-0.5)$ & $-1.5(-2.1,-0.8)$ \\
\hline Height-for-age Z-score: median (IQR) & $-1.7(-2.3,-1.0)$ & $-1.3(-2.0,-0.6)$ & $-1.9(-2.5,-1.3)$ \\
\hline BMI-for-age Z-score: median (IQR) & $-0.5(-1.1,0.1)$ & $-0.5(-1.1,0.0)$ & $-0.5(-1.1,0.1)$ \\
\hline \multicolumn{4}{|l|}{ HIV viral load } \\
\hline No value available & $240(40.7 \%)$ & $98(37.0 \%)$ & $142(43.7 \%)$ \\
\hline$<80$ (\% of those with values) & $267(76.3 \%)$ & $125(74.9 \%)$ & $142(77.6 \%)$ \\
\hline $80-399$ (\% of those with values) & $21(6.0 \%)$ & $11(6.6 \%)$ & $10(5.5 \%)$ \\
\hline 400-- (\% of those with values) & $62(17.7 \%)$ & $31(18.6 \%)$ & $31(16.9 \%)$ \\
\hline
\end{tabular}

*Voluntary decision since week 133 range.

ABC indicates abacavir; 3TC, lamivudine; ZDV, zidovudine; NVP, nevirapine; EFV, efavirenz; ALV, lopinavir/ritonavir (Aluvia); ART, antiretroviral therapy; IQR, interquartile

$(P>0.1)$, but subscapular and supra-iliac skinfold Z-scores were slightly but significantly higher in those receiving zidovudine longterm (Arm-A/B vs. C $P=0.006, P=0.02$, respectively).

There were also no significant differences in skinfold thickness, hip, mid-thigh and mid-upper arm body circumferences and their Z-scores, or waist-arm ratio, between efavirenz-containing and nevirapine-containing regimens (adjusted $P>0.09$; Table 1), but waist circumference (and Z-score) and waist-hip ratio were slightly but significantly lower in those receiving efavirenz in the metabolic substudy $(P=0.04,0.03$ and 0.02 , respectively; waisthip ratio $Z$-score marginally lower, $P=0.06$ ). In all 1206 children, there were no differences in waist and hip circumference $Z$-scores between children receiving efavirenz or nevirapine in the long-term (Figure 1). Hip circumference was slightly but significantly higher in those receiving efavirenz at ART initiation and then over the first 60 weeks on ART, leading to a significant difference overall
$(P=0.01)$ (driven by greater nevirapine use in younger children) However, there was no evidence of difference overall in waist circumference or waist-hip ratio ( $P=0.13$ and 0.12 , respectively), and no differences in waist/hip circumferences or their ratio by randomized ART-strategy $(P>0.2)$.

Cluster analysis identified 4 main groups of children: those relatively large-for-age on all measurements (relatively high Z-scores) but with higher body circumferences than skinfold thicknesses (ie, very lean, $\mathrm{n}=103,29.1 \%$ Arm-C); relatively large-forage on all measurements but with higher skinfold thicknesses than body circumferences (plump; $n=70,42.9 \%$ Arm-C); intermediatefor-age on all measurements $(n=337,33.2 \%$ Arm-C) or low-forage on all measurements, although typically with even lower body circumferences than skinfold thicknesses $(n=54,25.9 \%$ Arm-C). Proportions in Arm-C did not differ significantly between the 4 groups (Arm-C vs. A/B $P=0.17$ ). 
At 3 years, the sum of the 4 skinfolds was significantly $(P<0.05)$ and independently higher in children receiving longterm zidovudine (Arm-C) versus no (Arm-A) or short-term (ArmB) zidovudine $[$ Arm-C vs. A/B adjusted difference $+0.49 \mathrm{~mm}(95 \%$ confidence interval $(\mathrm{CI}),+0.02,+0.97) ; P=0.04]$, girls, Ugandan children (vs. Zimbabwean) and those with higher current BMI-forage (Table 2). In children with pre-ART height-for-age Z-score $\geq 3$, sum-of-skinfolds 3 years after ART initiation increased significantly with higher pre-ART height-for-age $(P<0.0001)$; in children with height-for-age $\leq 3$ pre-ART, there was no evidence of association $(P=0.44)$. Current height-for-age had no independent effect $(P=0.29)$ after adjustment for pre-ART height-for-age (Spearman correlation $=0.73$ ). Under 10 years, there was only weak association between age and sum-of-skinfolds $(P=0.07)$; over 10 years, sum-of-skinfolds increased significantly with older age $(P<0.0001)$, likely reflecting pubertal effects.

\section{Biochemistry}

Biochemistry was available for 319 children, $256(80.3 \%)$ known to have fasted for $>6$ hours $(75.2 \%$ Arm-A, $78.0 \%$ Arm-B, $87.6 \%$ Arm-C; $P=0.06)$. Mean total and HDL cholesterolwere significantly lower with long-term zidovudine (Arm-C, HDL $0.8 \mathrm{mmol} / \mathrm{L}$ ) compared to no (Arm-A, $1.2 \mathrm{mmol} / \mathrm{L}$ ) or short-term zidovudine

(a) waist Z-score

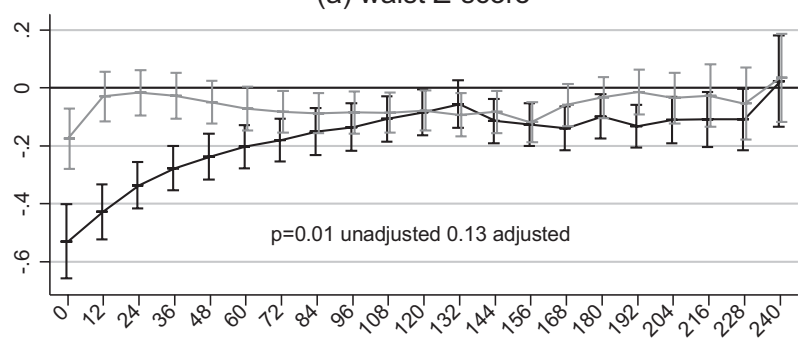

(b) hip Z-score

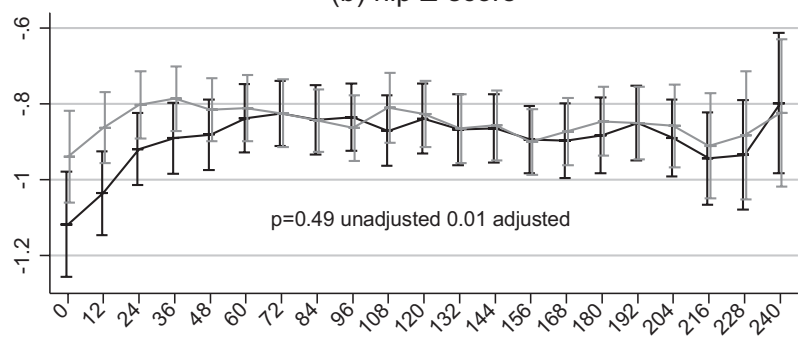

(c) waist-hip ratio Z-score

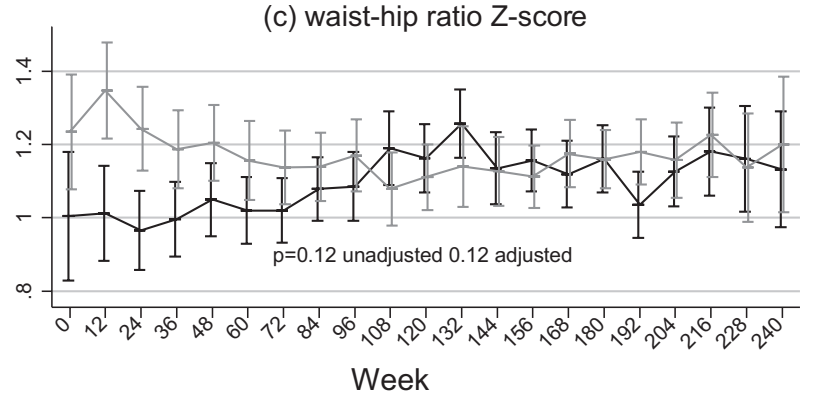

- NVP-containing initial regimen _ EFV-containing initial regimen

Note: NVP=nevirapine, EFV=efavirenz, ART=antiretroviral therapy

FIGURE 1 Long-term impact of efavirenz versus nevirapinebased ART on waist and hip circumferences in children initiating ART aged over 3 years
(Arm-B, $1.2 \mathrm{mmol} / \mathrm{L}$ ) (one-way analysis of variance $P<0.0001$ ), with LDL similar across ART-strategy (Table 3). Mean triglycerides were $0.8 \mathrm{mmol} / \mathrm{L}$, with no significant differences by ART-strategy; consequently the HDL/triglyceride ratio was significantly lower with long-term zidovudine (Arm-C, 1.4) than no (Arm-A, 2.1) or short-term zidovudine (Arm-B, 2.4) $(P<0.0001)$. Similarly, the total cholesterol/triglyceride ratio was significantly lower in Arm-C (5.6) than Arm-A (7.1) or Arm-B (7.5) $(P=0.01)$. Eighty-one children $(25.4 \%)$ had elevated total cholesterol, fewer in Arm-C $(P=0.008$; Table 4$) ; 39 / 81$ had a family history of hypertension and 13 of stroke. However, $174(55.1 \%)$ children still had abnormally low HDL, more in Arm-C $(P<0.0001)$. Mean glucose, total protein and albumin were $4.74 \mathrm{mmol} / \mathrm{L}, 76.9 \mathrm{~g} / \mathrm{L}$ and $40.2 \mathrm{~g} / \mathrm{L}$, respectively, with no significant differences between long-term, short-term or no zidovudine.

LDL cholesterol was significantly higher in those taking efavirenz-containing versus nevirapine-containing regimens [adjusted difference $+0.44 \mathrm{mmol} / \mathrm{L}(95 \% \mathrm{CI},+0.18,+0.70)$; $P=0.001]$; HDL was nonsignificantly lower $[-0.12 \mathrm{mmol} / \mathrm{L}(95 \%$ $\mathrm{CI},-0.27,+0.04)]$, as was albumin $[-1.46 \mathrm{~g} / \mathrm{L}(95 \% \mathrm{CI},-3.00$, $+0.08)]$. There were no other significant biochemical differences between efavirenz-containing and nevirapine-containing groups.

Although there was weak correlation between total cholesterol and triglycerides (Spearman correlation $=0.30$ ), pairwise correlations between lipid fractions, triglycerides and the other biochemical measurements were low (Spearman correlation $<0.3$ ). Biochemical and anthropometric measurements were uncorrelated (Spearman rho $<0.2$ ).

\section{Physician Assessment of Changes in Body Shape Since ART Initiation}

Any fat loss since ART initiation was reported in only 7/419 children (1.7\%) (all mild-moderate), 4 also with more visible veins reported (not reported in any other children). Five of the 7 children reported to have any fat loss were also classified as having clinical signs/symptoms of abnormal fat wasting (all Ugandan); the other 2 children (Zimbabwean) were not. A further 3 children were also classified as having clinical signs/symptoms of abnormal fat wasting (changes in body shape data were missing). Hence in total $8 / 579$ children $(1.4 \%)$ had clinical signs/symptoms of fat wasting (Arm-A: 3/188; Arm-B: 3/198; Arm-C: 2/193), 5 grade 1 (2 Arm-A,1 Arm-B, 2 Arm-C) and the remainder grade 2. Of the 6 in Arm A/B (receiving abacavir long-term), 4 had received efavirenz, 1 nevirapine and 1 had substituted efavirenz with nevirapine for lipodystrophy.

Any fat gain since ART initiation was reported in 174/419 children (41.5\%), only 1 severe (face and buttocks). Only 2 children had clinical signs/symptoms of abnormal fat accumulation reported by clinicians, both grade 1 ( 1 Arm-A, 1 Arm-C; both had received efavirenz, although only to week 36 in Arm-C).

Among all 1206 children/adolescents, there were only 8 ART-modifications for lipoatrophy/lipodystrophy (two $<3$ years on ART and 3 in the children above with clinical signs/symptoms of abnormal fat wasting). Efavirenz was substituted with nevirapine in 2 children for gynecomastia (1 Arm-A, 1 Arm-B) and 3 for lipodystrophy (1 Arm-A, 2 Arm-B). Two children substituted zidovudine with nevirapine for lipoatrophy in Arm-C; and another Arm-C child, already off zidovudine because of anemia, substituted stavudine with tenofovir.

\section{DISCUSSION}

Detailed investigation of a large, nonblinded group of children randomized to first-line ART containing long-term, shortterm or no zidovudine, found no increased risk of lipoatrophy/ 
TABLE 2. Independent Predictors of the Sum of 4 Skinfold Measurements 3 Years After ART Initiation

\begin{tabular}{|c|c|c|}
\hline Factor & $\begin{array}{c}\text { Estimate }(\mathrm{mm}) \\
(95 \% \mathrm{CI})\end{array}$ & $P$ \\
\hline Allocated treatment strategy, vs. Arm A (3TC/ABC/NNRTI)* & & 0.13 \\
\hline Arm B (36 weeks ZDV) & $0.1(-1.1,1.2)$ & 0.87 \\
\hline Arm C (long-term ZDV) & $1.0(-0.1,2.1)$ & 0.07 \\
\hline Male & $-3.8(-4.7,-2.9)$ & $<0.0001$ \\
\hline Height-for-age Z-score at ART initiation (per unit Z-score higher) & & $<0.0001$ \\
\hline Z-score at ART initiation $\leq-3$ & $-0.3(-1.2,0.5)$ & 0.44 \\
\hline Z-score at ART initiation $>-3$ & $1.1(0.6,1.7)$ & $<0.0001$ \\
\hline BMI-for-age Z-score at 3-year measurement & $2.6(2.1,3.1)$ & $<0.0001$ \\
\hline Age at 3-year measurement (per year increase) & & $<0.0001$ \\
\hline$<10$ years & $0.24(-0.02,0.50)$ & 0.07 \\
\hline$\geq 10$ years & $1.5(1.3,1.8)$ & $<0.0001$ \\
\hline Harare & $-3.4(-4.4,-2.4)$ & $<0.0001$ \\
\hline $\begin{array}{l}\text { Reference category: Ugandan girl, aged } 10 \text {, in Arm A (3TC/ABC/NNRTI); with height-for-age }-2 \text { at } \\
\text { ART initiation and BMI-for-age }-1 \text { three years after ART initiation }\end{array}$ & $28.6(25.4,31.8)$ & $<0.0001$ \\
\hline
\end{tabular}

* Arm-C versus A/B combined $P=0.04$ [adjusted difference $+0.49 \mathrm{~mm}(95 \% \mathrm{CI}, 0.02,0.97)$ ].

$\mathrm{ABC}$ indicates abacavir, 3TC, lamivudine; ZDV, zidovudine.

Factors considered that were not included in the final model were pre-ART WHO stage, CD4\% and BMI-for-age; 3-year CD4\% and height-for-age; change in CD4\%, height-forage and BMI-for-age during first 6 months on ART; monitoring randomization. ART strategy randomization was included regardless of statistical significance. Weight-for-age was strongly associated with height-for-age and therefore was not considered, nor was viral load as only $56 \%$ of children had a value available.

body shape changes with long-term zidovudine use using WHO weight-band ART doses through 3 years, and generally similar impact of zidovudine+lamivudine and abacavir+lamivudine NRTI backbones. Along with reassuring data on low incidence of excess anemia with zidovudine already reported, ${ }^{31}$ these similar lipodystrophy rates provide important reassurance where first-line pediatric regimens have changed from stavudine to zidovudine, as there have been concerns that zidovudine (also a thymidine analogue) could still cause lipoatrophy/lipodystrophy, albeit at lower rates than stavudine. The substantially lower potential for lipoatrophy from zidovudine is supported by reversal of signs in Thai children switched from stavudine to zidovudine-containing regimens. ${ }^{39}$ Efficacy is also important when considering the relative merits of different pediatric ART regimens. However, ARROW children receiving long-term zidovudine were all on triple NRTI maintenance regimens. While lipoatrophy/body shape changes on this regimen are plausibly generalizable to standard longterm zidovudine+lamivudine+NNRTI regimens, poorer virologic response with 3 NRTI regimens over the longer-term ${ }^{31}$ is unlikely to reflect responses on zidovudine+lamivudine+NNRTI. In children, abacavir+lamivudine was virologically superior to zidovudine+lamivudine in a randomized comparison over 5 years ${ }^{40,41}$ but inferior to stavudine+lamivudine in a South African cohort study. ${ }^{42}$ In adults, a meta-analysis of 9 randomized trials $(\mathrm{n}=2159)$ concluded there was no virologic difference between zidovudine-containing and stavudine-containing regimens. ${ }^{43}$ The relative virologic efficacy of stavudine-containing, zidovudinecontaining and abacavir-containing NRTI backbones in children is therefore currently unclear, but will be addressed by the CHAPAS-3 trial (www.chapas3trial.org).

Overall, lipodystrophy rates among ARROW children were low compared to previous studies in African ART-treated children, ${ }^{13,14,20}$ possibly because stavudine (as a first-line substitution) and protease inhibitor (as second-line) use was minimal. Alternatively, observed rates may highlight challenges in applying subjective lipodystrophy definitions when children's body shapes are changing, given low clinical suspicion without stavudine/protease inhibitors. As lipodystrophy has rarely been assessed blinded to ART (nor did we do this), it is impossible to exclude the potential for ascertainment bias, although this is less likely with skinfold and body circumference measurements. Another study limitation is that we did not assess anthropometry or metabolic parameters pre-ART, so we could only compare children cross-sectionally after 3 years on ART (albeit based on randomized groups), rather than comparing changes from ART initiation. The relatively low pre-ART weight-for-age, which would be expected to be associated with low cholesterol and raised triglycerides, might have shifted the balance between harmful and beneficial effects of ART on anthropometric/ metabolic parameters toward benefit in the short-term to mediumterm. $^{44}$

We found children receiving long-term zidovudine had significantly lower HDL and total cholesterol (likely driven by lower HDL) than those receiving NNRTI-based ART long-term, leading to substantially lower HDL/triglyceride and total cholesterol/ triglyceride ratios. Lower HDL could reflect a greater tendency to dyslipidemia with long-term zidovudine, or could be because children receiving long-term zidovudine were all on 3 NRTI maintenance regimens with no NNRTI. How potentially greater risk from low HDL balances against lower risk from reduced total cholesterol/triglyceride ratio is unclear, but an abnormal HDL/triglyceride ratio has been strongly associated with coronary disease in adults, suggesting atherogenic effects. ${ }^{45}$ We also found significantly higher LDL, and a trend toward lower HDL cholesterol, in children receiving efavirenz versus nevirapine. Increases in nonfasting HDL cholesterol were lower among adults receiving efavirenz compared with nevirapine, ${ }^{46}$ and in a large Tanzanian cohort. ${ }^{44}$ Although these studies found no significant differences in calculated (not measured) LDL, 1 randomized trial reported significant decreases in LDL cholesterol following switch from efavirenz-containing to nevirapine-containing ART in adults with dyslipidemia. ${ }^{47}$ No child in this substudy was receiving zidovudine+lamivudine+efavirenz (used very rarely in ARROW as a toxicity substitution), but, together, these results suggest that this combination could more likely lead to disturbed lipid profiles over the longer-term. As this regimen is commonly used globally, and is likely to become even more so given recent licensing of efavirenz in children $<3$ years ${ }^{48}$ and suggestion of improved virologic suppression versus nevirapine, ${ }^{49,50}$ this should be investigated in future studies. However, our findings show that such studies will need to directly measure HDL, and ideally also LDL.

Despite their statistical significance, most changes in lipids were still within the normal range. The only significant difference in graded toxicity was for total cholesterol, where $13.3 \%$ of those receiving long-term zidovudine had elevated values (all 


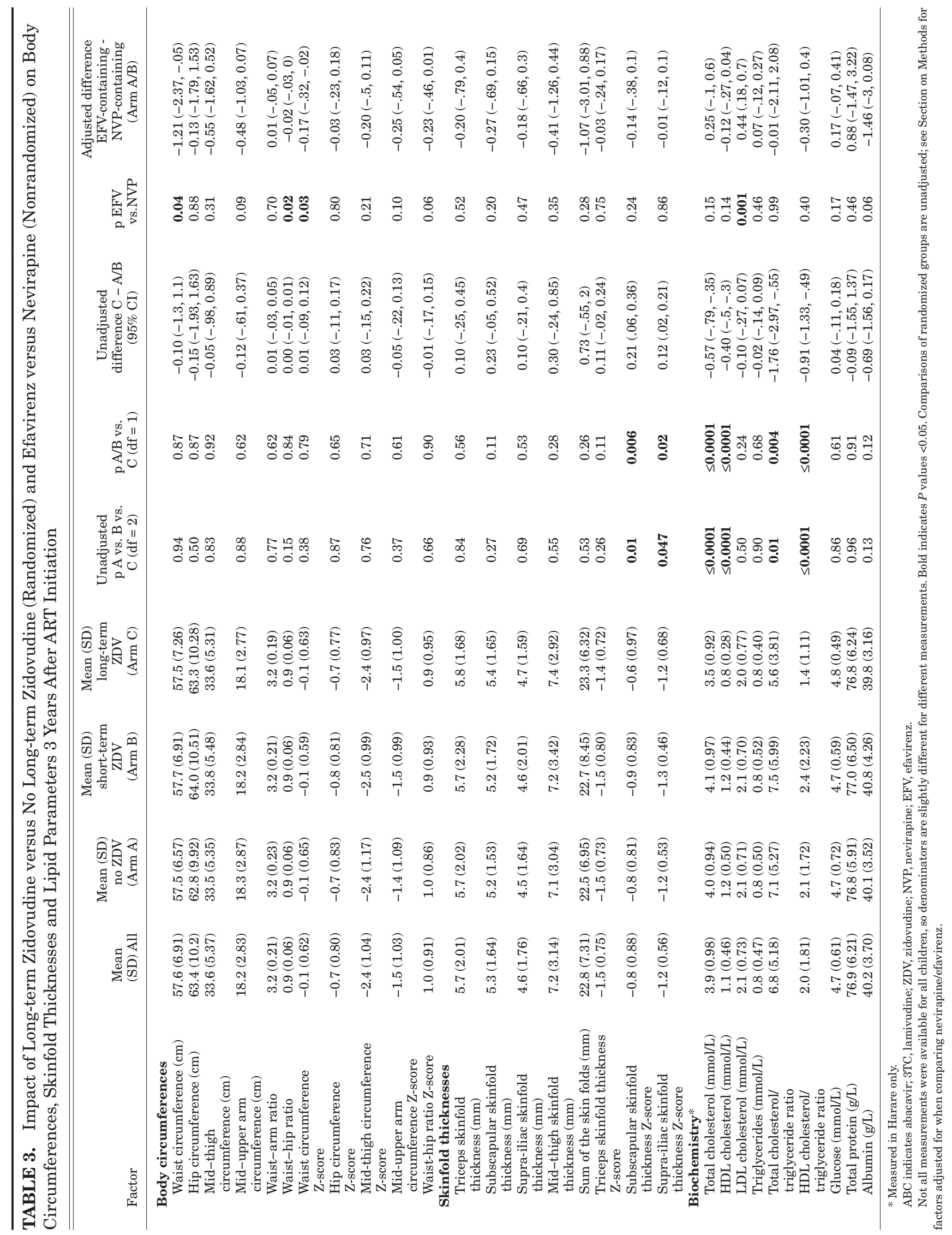


TABLE 4. Graded Toxicity in Cholesterol, Lipid Fractions, Triglycerides, Glucose and Albumin 3 Years After ART Initiation

\begin{tabular}{|c|c|c|c|c|}
\hline & $\begin{array}{c}\operatorname{Arm} \mathrm{A}(\text { no ZDV) } \\
\mathrm{N}=105\end{array}$ & $\begin{array}{c}\text { Arm B (36 weeks ZDV) } \\
\text { N = } 109\end{array}$ & $\begin{array}{l}\text { Arm C (long-term ZDV) } \\
\qquad \mathrm{N}=105\end{array}$ & $\begin{array}{l}\text { Total } \\
\mathrm{N}=319\end{array}$ \\
\hline Total cholesterol (mmol/L) & & & & $P=0.008$ \\
\hline Normal: $<4.4$ & $73(69.5 \%)$ & $74(67.9 \%)$ & $91(86.7 \%)$ & $238(74.6 \%)$ \\
\hline Grade 1: 4.40-5.15 & $15(14.3 \%)$ & $21(19.3 \%)$ & $8(7.6 \%)$ & $44(13.8 \%)$ \\
\hline Grade $2: 5.16-7.77$ & $17(16.2 \%)$ & $13(11.9 \%)$ & $6(5.7 \%)$ & $36(11.3 \%)$ \\
\hline Grade $3:>7.77$ & $0(0.0 \%)$ & $1(0.9 \%)$ & $0(0.0 \%)$ & $1(0.3 \%)$ \\
\hline HDL cholesterol (mmol/L) & & & & $P<0.0001$ \\
\hline Normal: $\geq 1.04$ & $55(52.9 \%)$ & $73(67.0 \%)$ & $14(13.6 \%)$ & $142(44.9 \%)$ \\
\hline Abnormal: $<1.04$ & $49(47.1 \%)$ & $36(33.0 \%)$ & $89(86.4 \%)$ & $174(55.1 \%)$ \\
\hline Missing & 1 & 0 & 2 & 3 \\
\hline LDL cholesterol (mmol/L) & & & & $P=0.20$ \\
\hline Normal: $<2.85$ & $84(80.8 \%)$ & $94(86.2 \%)$ & $92(87.6 \%)$ & $270(84.9 \%)$ \\
\hline Grade 1: 2.85-3.34 & $15(14.4 \%)$ & $7(6.4 \%)$ & $6(5.7 \%)$ & $28(8.8 \%)$ \\
\hline Grade $2: 3.35-4.90$ & $5(4.8 \%)$ & $8(7.3 \%)$ & $7(6.7 \%)$ & $20(6.3 \%)$ \\
\hline Missing & 1 & 0 & 0 & 1 \\
\hline Triglycerides (mmol/L) & & & & $P=1.00$ \\
\hline Normal: $<5.65$ & $105(100.0 \%)$ & $109(100.0 \%)$ & $103(100.0 \%)$ & $317(100.0 \%)$ \\
\hline Missing & 0 & 0 & 2 & 2 \\
\hline Glucose (mmol/L) & & & & $P=0.18$ \\
\hline Low-grade 2: $2.22-3.06$ & $1(1.0 \%)$ & $0(0.0 \%)$ & $0(0.0 \%)$ & $1(0.3 \%)$ \\
\hline Low-grade 1: 3.05-3.55 & $0(0.0 \%)$ & $0(0.0 \%)$ & $0(0.0 \%)$ & $0(0.0 \%)$ \\
\hline Normal: $3.65-6.10$ & $97(93.2 \%)$ & $107(98.2 \%)$ & $103(99.0 \%)$ & $307(96.8 \%)$ \\
\hline High-grade $1: 6.11-6.94$ & $3(2.9 \%)$ & $2(1.8 \%)$ & $1(1.0 \%)$ & $6(1.9 \%)$ \\
\hline High-grade $2: 6.95-13.88$ & $3(2.9 \%)$ & $0(0.0 \%)$ & $0(0.0 \%)$ & $3(0.9 \%)$ \\
\hline Missing & 1 & 0 & 1 & 2 \\
\hline Albumin (g/L) & & & & $P=0.68$ \\
\hline Normal: $\geq 35$ & $99(95.2 \%)$ & $102(93.6 \%)$ & $100(95.2 \%)$ & $301(94.7 \%)$ \\
\hline Grade 1: $30-<35$ & $5(4.8 \%)$ & $5(4.6 \%)$ & $5(4.8 \%)$ & $15(4.7 \%)$ \\
\hline Grade $2: 20-29$ & $0(0.0 \%)$ & $2(1.8 \%)$ & $0(0.0 \%)$ & $2(0.6 \%)$ \\
\hline Missing & 1 & 0 & 0 & 1 \\
\hline
\end{tabular}

ZDV indicates zidovudine.

Tests exclude missing observations. Total and LDL cholesterol, triglycerides, glucose and albumin were considered abnormal according to the Division of AIDS grading ${ }^{37}$; HDL was considered abnormal $<1.04 \mathrm{mmol} / \mathrm{L}(40 \mathrm{mg} / \mathrm{dL}){ }^{38}$ Children with elevated total cholesterol were receiving lamivudine+abacavir+nevirapine (44 children), lamivudine+abacavir+efavirenz (21), lamivudine+abacavir+zidovudine (12), lopinavir/ ritonavir+zidovudine+didanosine (2), lopinavir/ritonavir+lamivudine+didanosine (1) and lopinavir/ritonavir+efavirenz (1).

receiving 3NRTI maintenance), compared with $31.3 \%$ receiving NNRTI without zidovudine long-term; and HDL cholesterol, where $86.4 \%$ and $39.9 \%$ had abnormally low values respectively. However, most abnormalities were low grade (1-2); with the abacavir+lamivudine+NNRTI/3 NRTI long-term regimens used, we found very few children had sufficiently severe lipid abnormalities after 3 years on ART to consider switching or using lipid-lowering therapy. The modest nature of the changes, their unclear clinical significance and uncertainty regarding the role of pharmacologic interventions, suggest there is little reason to regularly monitor for lipid toxicity, as for other biochemical toxicities, ${ }^{31}$ particularly in low-income settings. However, the impact over timescales longer than 3 years is unknown, although previous data in children suggest that the most pronounced lipid changes occur during the first year on ART. ${ }^{51}$

The major limitation of our study is its cross-sectional design, a consequence of being setup after trial recruitment had ended. However, zidovudine comparisons are randomized, eliminating 1 potential source of bias. Furthermore, those receiving long-term zidovudine were on a 3NRTI regimen, which is only recommended in WHO guidelines during tuberculosis treatment. Although nevirapine and efavirenz were not randomized, both drugs were used in substantial numbers in each center, based mainly on age and individual recruiting clinician preference. Another limitation is the lack of country-specific reference values, necessitating the use of Dutch reference data, ${ }^{34,35}$ also used in Black African children in the UK. This makes interpreting absolute Z-scores difficult. Interestingly, Ugandan/Zimbabwean children appeared relatively similar to Dutch children on central measures, but had substantially more muscular/leaner extremities. This could be because of nondrug-specific ART (or even HIV) effects in these children, or to higher values in uninfected normal Dutch than Ugandan/Zimbabwean children. The lack of evidence supporting associations between abacavir and lipoatrophy, the low rates of lipoatrophy reported by clinicians regardless of ART exposure, and the generally more active lifestyle of African children support the former explanation. However, differences in Z-scores between groups are likely far less affected than absolute values. We found little or no evidence of differences between groups of Ugandan/ Zimbabwean children in unadjusted and adjusted analyses, so using different reference values would have been unlikely to alter this. Direct LDL and HDL measurement in mostly fasted children was 1 study advantage. However, metabolic assays were only performed in Zimbabwe, whereas most children with abnormal clinical signs/ symptoms of lipodystrophy were Ugandan, making comparisons of metabolic parameters between those with and without lipodystrophy impossible. Finally, we investigated a large number of different parameters; some results (eg, higher subscapular and supra-iliac skinfolds with long-term zidovudine) could therefore be false-positives from multiple testing.

In summary, we found no evidence that long-term zidovudine was associated with greater rates of lipodystrophy, or more severe abnormalities in body circumferences/skinfold thicknesses, than abacavir+lamivudine-based regimens in a randomized comparison 3 years after ART initiation, with only relatively small differences in HDL and total cholesterol. These findings suggest that both zidovudine and abacavir are similarly safe NRTI options with respect to lipodystrophy/lipoatrophy/lipid measurements, which is 
reassuring given the wholescale move toward these regimens across Africa and the necessity for these children to receive ART. We also found no, or relatively small, differences between efavirenz and nevirapine. While these are longer-term data than those published to date on zidovudine-based ART in resource-limited settings, they are still short-term in the context of lifelong ART; given the severe adverse consequences of lipodystrophy, particularly for adolescents, and its impact on adherence, longer-term studies will be important.

\section{ACKNOWLEDGMENTS}

We thank the children, caregivers and staff from all the centers participating in the ARROW trial, and the ARROW Trial Steering Committee for access to data.

MRC/UVRI Uganda Research Unit on AIDS, Entebbe, Uganda: P. Munderi, P. Nahirya-Ntege, R. Katuramu, J. Lutaakome, F. Nankya, G. Nabulime, I. Sekamatte, J. Kyarimpa, A. Ruberantwari, R. Sebukyu, G. Tushabe, D. Wangi, M. Musinguzi, M. Aber, L. Matama, D. Nakitto-Kesi. Joint Clinical Research Centre, Kampala, Uganda: P. Mugyenyi, V. Musiime, R. Keishanyu, V.D. Afayo, J. Bwomezi, J. Byaruhanga, P. Erimu, C. Karungi, H. Kizito, W.S. Namala, J. Namusanje, R. Nandugwa, T.K. Najjuko, E. Natukunda, M. Ndigendawani, S.O. Nsiyona, R. Kibenge, B. Bainomuhwezi, D. Sseremba, J. Tezikyabbiri, C.S. Tumusiime, A. Balaba, A. Mugumya, F. Nghania, D. Mwebesa, M. Mutumba, E. Bagurukira, F. Odongo, S. Mubokyi, M. Ssenyonga, M. Kasango, E. Lutalo, P. Oronon. University of Zimbabwe, Harare, Zimbabwe: K.J. Nathoo, M.F. Bwakura-Dangarembizi, F. Mapinge, E. Chidziva, T. Mhute, T. Vhembo, R. Mandidewa, M. Chipiti, R. Dzapasi, C. Katanda, D. Nyoni, G.C. Tinago, J. Bhiri, S. Mudzingwa, D. Muchabaiwa, M. Phiri, V. Masore, C.C. Marozva, S.J. Maturure, S. Tsikirayi, L. Munetsi, K.M. Rashirai, J. Steamer, R. Nhema, W. Bikwa, B. Tambawoga, E. Mufuka. Baylor College of Medicine Children's Foundation Uganda, Mulago Hospital Uganda: A. Kekitiinwa, P. Musoke, S. Bakeera-Kitaka, R. Namuddu, P. Kasirye, A. Babirye, J. Asello, S. Nakalanzi, N.C. Ssemambo, J. Nakafeero, J. Tikabibamu, G. Musoba, J. Ssanyu, M. Kisekka. MRC Clinical Trials Unit, London, UK: D.M. Gibb, M.J. Thomason, A.S. Walker, A.D. Cook, A.J. Szubert, B. Naidoo-James, M.J. Spyer, C. Male, A.J. Glabay, L.K. Kendall, J. Crawley, A.J. Prendergast.

Independent ARROW Trial Monitors: I. Machingura, S. Ssenyonjo. Trial Steering Committee: I. Weller (Chair), E. Luyirika, H. Lyall, E. Malianga, C. Mwansambo, M. Nyathi, F. Miiro, D.M. Gibb, A. Kekitiinwa, P. Mugyenyi, P. Munderi, K.J. Nathoo, A.S. Walker; Observers: S. Kinn, M. McNeil, M. Roberts, W. Snowden. Data and Safety Monitoring Committee: A. Breckenridge (Chair), A. Pozniak, C. Hill, J. Matenga, J. Tumwine. Endpoint Review Committee (independent members): G. Tudor-Williams (Chair), $H$. Barigye, H.A. Mujuru, G. Ndeezi; Observers: S. Bakeera-Kitaka, M.F. Bwakura-Dangarembizi, J. Crawley, V. Musiime, P. NahiryaNtege, A. Prendergast, M. Spyer.

Economics Group: P. Revill, T. Mabugu, F. Mirimo, S. Walker, M.J. Sculpher.

ARROW was funded by the UK Medical Research Council and the UK Department for International Development (DFID). ViiV Healthcare/GlaxoSmithKline donated first-line drugs for ARROW.

\section{REFERENCES}

1. Alam N, Cortina-Borja M, Goetghebuer T, et al; European Paediatric HIV and Lipodystrophy Study Group in EuroCoord. Body fat abnormality in HIV-infected children and adolescents living in Europe: prevalence and risk factors. J Acquir Immune Defic Syndr. 2012;59:314-324.

2. Amaya RA, Kozinetz CA, McMeans A, et al. Lipodystrophy syndrome in human immunodeficiency virus-infected children. Pediatr Infect Dis J. 2002;21:405-410
3. Arpadi SM, Bethel J, Horlick M, et al. Longitudinal changes in regional fat content in HIV-infected children and adolescents. AIDS. 2009;23:15011509 .

4. Aurpibul L, Puthanakit T, Lee B, et al. Lipodystrophy and metabolic changes in HIV-infected children on non-nucleoside reverse transcriptase inhibitor-based antiretroviral therapy. Antivir Ther. 2007;12:1247-1254.

5. Badillo K, Prieto L, Toledano M, et al. Characteristics of human immunodeficiency virus-1 infected children receiving highly active antiretroviral therapy: a cross-sectional study. An Pediatr (Barc) 2012;76:317-323.

6. Beregszaszi M, Dollfus C, Levine M, et al. Longitudinal evaluation and risk factors of lipodystrophy and associated metabolic changes in HIV-infected children. J Acquir Immune Defic Syndr. 2005;40:161-168.

7. Ene L, Goetghebuer T, Hainaut M, et al. Prevalence of lipodystrophy in HIV-infected children: a cross-sectional study. Eur J Pediatr. 2007;166:1321

8. European Paediatric Lipodystrophy G. Antiretroviral therapy, fat redistribution and hyperlipidaemia in HIV-infected children in Europe. AIDS. 2004,18:1443-1451.

9. Innes S, Cotton MF, Haubrich R, et al. High prevalence of lipoatrophy in pre-pubertal South African children on antiretroviral therapy: a cross-sectional study. BMC Pediatr. 2012;12:183.

10. Jaquet D, Lévine M, Ortega-Rodriguez E, et al. Clinical and metabolic presentation of the lipodystrophic syndrome in HIV-infected children. AIDS 2000; $14: 2123-2128$

11. Jevtović D, Salemović D, Ranin J, et al. The prognosis of pediatric AIDS in serbia. Curr HIV Res. 2009;7:287-292.

12. Kanjanavanit $\mathrm{S}$, Puthanakit $\mathrm{T}$, Vibol U, et al; PREDICT study group. High prevalence of lipid abnormalities among antiretroviral-naive HIV-infected Asian children with mild-to-moderate immunosuppression. Antivir Ther. 2011;16:1351-1355.

13. Kinabo GD, Sprengers M, Msuya LJ, et al. Prevalence of lipodystrophy in HIV-infected children in Tanzania on highly active antiretroviral therapy. Pediatr Infect Dis J. 2013;32:39-44

14. Piloya T, Bakeera-Kitaka S, Kekitiinwa A, et al. Lipodystrophy among HIVinfected children and adolescents on highly active antiretroviral therapy in Uganda: a cross sectional study. J Int AIDS Soc. 2012;15:17427.

15. Alves C, Oliveira AC, Brites C. Lipodystrophic syndrome in children and adolescents infected with the human immunodeficiency virus. Braz J Infect Dis. 2008; 12:342-348

16. Arpadi SM, Cuff PA, Horlick M, et al. Lipodystrophy in HIV-infected children is associated with high viral load and low CD4+ -lymphocyte count and CD4+-lymphocyte percentage at baseline and use of protease inhibitors and stavudine. J Acquir Immune Defic Syndr. 2001;27:30-34.

17. Carter RJ, Wiener J, Abrams EJ, et al; Perinatal AIDS Collaborative Transmission Study-HIV Follow-up after Perinatal Exposure (PACTSHOPE) Group. Dyslipidemia among perinatally HIV-infected children enrolled in the PACTS-HOPE cohort, 1999-2004: a longitudinal analysis. $J$ Acquir Immune Defic Syndr. 2006;41:453-460.

18. Resino S, Palladino C, Lorente R, et al; Spanish Group of Pediatric HIV Infection. Association between lipodystrophy and leptin in human immunodeficiency virus-1-infected children receiving lopinavir/ritonavir-based therapy. Pediatr Infect Dis J. 2010;29:774-777.

19. UNAIDS. Global report: UNAIDS Report on the Global AIDS Epidemic 2012. Geneva, Switzerland: UNAIDS, 2012

20. Arpadi S, Shiau S, Strehlau R, et al. Metabolic abnormalities and body composition of HIV-infected children on Lopinavir or Nevirapine-based antiretroviral therapy. Arch Dis Child. 2013;98:258-264.

21. Musiime V, Cook A, Kayiwa J, et al. Anthropometric measurements and lipid profiles to detect early lipodystrophy in antiretroviral therapy experienced HIVinfected children in the CHAPAS-3-trial. Antivir Ther. 2014;19:269-276.

22. Ministry of Health - Kenya. Guidelines for Antiretroviral Therapy in Kenya. 4th ed. Available at: http://www.aidstar-one.com/sites/default/files/ treatment/national_treatment_guidelines/Kenya_2011_tagged.pdf. 2011. Accessed March 15, 2014.

23. Ministry of Health-Uganda. Addendum to the Antiretroviral Treatment Guidelines Available at: http://www.kisiizihospital.org.ug/wp-content/ uploadedfiles/2013/10/Addednum-National-ART-Rx-GuidelinesDec-2013.pdf. 2013. Accessed March 15, 2014.

24. RESAPSI/CNLS. Workshop Summary. Workshop on Strategies for Antiretroviral Therapy and Prevention of HIV Infection in Sub Saharan Africa (Saly, Senegal, 6-8 February 2014). 
25. Lucey JM, Hsu P, Ziegler JB. Tenofovir-related Fanconi's syndrome and osteomalacia in a teenager with HIV. BMJ Case Rep. [published online July 9, 2013]. doi: 10.1136/bcr-2013-008674.

26. Purswani M, Patel K, Kopp JB, et al; Pediatric HIVAIDS Cohort Study. Tenofovir treatment duration predicts proteinuria in a multiethnic United States Cohort of children and adolescents with perinatal HIV-1 infection. Pediatr Infect Dis J. 2013;32:495-500.

27. Medecins San Frontieres. Untangling the Web of Antiretroviral Price Reductions. 16th ed. Available at: http://d2pd3b5abq75bb.cloudfront. net/2013/09/11/10/25/44/896/MSF_Access_UTW_16th_Edition_2013.pdf. 2013. Accessed March 15, 2014.

28. de Waal R, Cohen K, Maartens G. Systematic review of antiretroviral-associated lipodystrophy: lipoatrophy, but not central fat gain, is an antiretroviral adverse drug reaction. PLoS One. 2013;8:e63623.

29. Shubber Z, Calmy A, Andrieux-Meyer I, et al. Adverse events associated with nevirapine and efavirenz-based first-line antiretroviral therapy: a systematic review and meta-analysis. AIDS. 2013;27:1403-1412.

30. Tukei VJ, Asiimwe A, Maganda A, et al. Safety and tolerability of antiretroviral therapy among HIV-infected children and adolescents in Uganda. $J$ Acquir Immune Defic Syndr. 2012;59:274-280.

31. Arrow Trial Team. Routine versus clinically driven laboratory monitoring and first-line antiretroviral therapy strategies in African children with HIV (ARROW): a 5-year open-label randomised factorial trial. Lancet 2013;381:1391-1403

32. World Health Organisation. Antiretroviral therapy for HIV infection in infants and children: Towards universal access. Recommendations for a public health approach. Available at: http://www.who.int/hiv/pub/guidelines/paediatric020907.pdf. Accessed May 3, 2013.

33. Lohman TG, Roche AF, Martorell R. Anthropometric Standardization Reference Manual. Champaign, IL: Human Kinetics Books; 1988.

34. Fredriks AM, van Buuren S, Fekkes M, et al. Are age references for waist circumference, hip circumference and waist-hip ratio in Dutch children useful in clinical practice? Eur J Pediatr. 2005;164:216-222.

35. Gerver WJM, de Bruin R. Paediatric Morphometrics: A Reference Manual. Maastricht, The Netherlands: Universitaire Pers Maastricht; 2001.

36. Wade AM, Ades AE. Age-related reference ranges: significance tests for models and confidence intervals for centiles. Stat Med. 1994;13:23592367.

37. National Institute for Allergy and Infectious Disease (NIAID). Division of AIDS Table for Grading the Severity of Adult and Pediatric Adverse Events. 2004. Available at: http://www.niaid.nih.gov/labsandresources/resources/ daidsclinrsrch/documents/daidsaegradingtable.pdf. Accessed March 10, 2014.

38. Expert Panel on Integrated Guidelines for Cardiovascular Health and Risk Reduction in Children and Adolescents. Expert Panel on integrated guidelines for cardiovascular health and risk reduction in children and adolescents: summary report. Pediatrics 2011,128:S213-S256.
39. Aurpibul L, Puthanakit T, Taejaroenkul S, et al. Recovery from lipodystrophy in HIV-infected children after substitution of stavudine with zidovudine in a non-nucleoside reverse transcriptase inhibitor-based antiretroviral therapy. Pediatr Infect Dis J. 2012;31:384-388.

40. Green H, Gibb DM, Walker AS, et al; Paediatric European Network for the Treatment of AIDS (PENTA). Lamivudine/abacavir maintains virological superiority over zidovudine/lamivudine and zidovudine/abacavir beyond 5 years in children. AIDS. 2007;21:947-955.

41. Paediatric European Network for Treatment of AIDS (PENTA). Comparison of dual nucleoside-analogue reverse-transcriptase inhibitor regimens with and without nelfinavir in children with HIV-1 who have not previously been treated: the PENTA 5 randomised trial. Lancet. 2002;359:733-740.

42. Technau KG, Schomaker M, Kuhn L, Moultrie H, Coovadia A, Eley B, et al. Virologic response in children treated with abacavir compared with stavudine-based antiretroviral treatment - a South African multi-cohort analysis. Pediatr Infect Dis J. 2014;33:617-622.

43. Spaulding A, Rutherford GW, Siegfried N. Stavudine or zidovudine in threedrug combination therapy for initial treatment of HIV infection in antiretroviral-naive individuals. Cochrane Database Syst Rev 2010:CD008651.

44. Liu E, Armstrong C, Spiegelman D, et al. First-line antiretroviral therapy and changes in lipid levels over 3 years among HIV-infected adults in Tanzania. Clin Infect Dis. 2013;56:1820-1828.

45. da Luz PL, Favarato D, Faria-Neto JR Jr, et al. High ratio of triglycerides to HDL-cholesterol predicts extensive coronary disease. Clinics (Sao Paulo). 2008;63:427-432.

46. van Leth F, Phanuphak P, Stroes E, et al. Nevirapine and efavirenz elicit different changes in lipid profiles in antiretroviral-therapy-naive patients infected with HIV-1. PLoS Med. 2004;1:e19.

47. Parienti JJ, Massari V, Rey D, et al; SIROCCO study team. Efavirenz to nevirapine switch in HIV-1-infected patients with dyslipidemia: a randomized, controlled study. Clin Infect Dis. 2007;45:263-266.

48. Federal Drug Authority. Sustiva (efavirenz) pediatric patients labeling update Available at: http://www.fda.gov/ForConsumers/ByAudience/ ForPatientAdvocates/HIVandAIDSActivities/ucm350744.htm. Accessed November 4, 2013.

49. Lowenthal ED, Ellenberg JH, Machine E, et al. Association between efavirenz-based compared with nevirapine-based antiretroviral regimens and virological failure in HIV-infected children. JAMA. 2013;309:1803-1809.

50. World Health Organisation. Consolidated guidelines on the use of antiretroviral drugs for treating and preventing HIV infection: recommendations for a public health approach. Available at: http://www.who.int/hiv/pub/guidelines/arv2013/download/en/index.html. Accessed March 10, 2014.

51. Rhoads MP, Lanigan J, Smith CJ, et al. Effect of specific ART drugs on lipid changes and the need for lipid management in children with HIV. J Acquir Immune Defic Syndr. 2011;57:404-412. 